\title{
COMMUNITY ARCHITECTURE: THE USE OF PARTICIPATORY DESIGN IN THE DEVELOPMENT OF A COMMUNITY HOUSING PROJECT IN THE PHILIPPINES
}

\author{
${ }^{1}$ Danilo V. RAVINA, ${ }^{2}$ Rowell Ray Lim SHIH, ${ }^{3}$ Gabriella MEDVEGY \\ ${ }^{1,2}$ Breuer Marcel Doctoral School, Faculty of Engineering and Information Technology \\ University of Pecs, Boszorkany u. 2, Pecs, Hungary and \\ Department of Architecture. School of Architecture, Fine Arts and Design \\ University of San Carlos Technological Center, Cebu City, Cebu, Philippines \\ e-mail: 1dravina@yahoo.com, ${ }^{2}$ rowellshih@yahoo.com \\ ${ }^{3}$ Faculty of Engineering and Information Technology, University of Pécs \\ Boszorkány u. 2, H-7624 Pécs, Hungary, e-mail: medvegygabriella@mik.pte.hu
}

Received 9 October 2017; accepted 2 March 2018

\begin{abstract}
This study exhibits the use of participatory design in the development of a community housing project for the twelve family members of the Donnaville Homeowners Association in Barangay 177, Caloocan City, Philippines. All families have been living as informal settlers of which portions of it were considered unsafe due to recurrent flooding during heavy rains. The housing project study was part of a workshop initiated by members of the Community Architecture Network. In order to achieve this methodology, the community architects arranged workshops between members of the families. The members were divided into teams that worked separately and then collectively identify strategies in improving the design and layout of the housing unit according to the needs of each family. The teams identified various interventions in order to effectively reduce the cost of each new unit. Finally, through comprehensive discussions and exchanges between the members, the resulting layout and schematic design of the housing unit were achieved that was desirable to the families. By using participatory design in the development of a project, in this case, a community housing unit, user acceptance is therefore increased and rejection is reduced by the stakeholders.
\end{abstract}

Keywords: Community architecture, Participatory design, Philippines housing project

\section{Introduction}

Studies have shown how government initiated housing projects fail because of the absence of community participation [1]. The construction of high-rise apartment buildings in the US and UK during the early part of the 1930's, after demolishing poor existing neighbourhoods, was a good example of government initiated projects without the involvement of communities [2]. Most of these projects failed in improving the 
living conditions of their inhabitants and were demolished after a few years [2], [3]. Currently, conventional architecture and planning rooted in the authoritarian management by professionals have clearly been unsuccessful [4], whereas studies have shown that the need to forge a partnership between a local community and support organizations is crucial for effective community restoration [5], [6], [7]. As a result, involving stakeholders in various design development projects has become increasingly common for different societal contexts [8], as in urban [2] and community planning [9]. By allowing people to be involved in shaping their environment is what community architecture movement has been exploring over the past few years [10]. As an umbrella under community architecture, participatory design involves the stakeholders at all stages of the design process [11]. While participatory design originated in Scandinavia with its workplace democracy labour movement of the 70's for engaging people [12], [13], the aim was not only to gain users' expectations about new skills but also to enable their democratic right to participate in design decisions affecting them [14]. The origins of participatory design is therefore said to lie in the principles of participatory democracy, in which decision-making is shared and decentralized. Thus, the central idea in the methodology of participative design is that those who are affected by what is designed should actively participate in the design process and should be able to secure already-existing skills and resources [15], [16], [13]. In this paper, a participatory design workshop was carried out in the community of the Donnaville Homeowners Association (DHA) in Barangay 177 of Caloocan City, Philippines. This paper presents a comprehensive case study to demonstrate the use of collaborative action plans and workshops in order to plan and design a housing community for the members of the homeowners. Although the government initiated Foundation for the Development of the Urban Poor (FDUP) provided their own schematic site and housing plans to the members of the association, the resulting cost of the houses was deemed to be unaffordable by family members. Because of this, the family members began to initialize ways in order to produce other solutions in order to make the new houses more affordable. The family members then approached the Community Architects Network (CAN) for assistance. The CAN is a program under the Asian Coalition for Housing Rights (ACHR) and is composed of architects, engineers and planners from the Philippines, Indonesia and Canada. In order to address the needs of the homeowners, it is necessary to develop collaborative action plans in considering the conditions of the community. The community architects would propose an alternative schematic design output for the family members of Donnaville Homeowners Association in order to produce a housing unit, which is affordable and responsive to the unique requirements of the family members.

\subsection{Profile of Donnaville Homeowners Association}

The Donnaville Homeowners Association was established in 2011 and is solely registered with the Philippines Housing and Land Use Regulatory Board (HLURB) in May 2012. However, after the devastating onslaught of typhoon Ketsana in 2009, the location of the DHA was identified as a high-risk area by the Local Housing Office (LHO). During the typhoon mapping, six families are revealed to be living within the prohibited three meter easement of a creek while the other six families are illegally 
occupying areas designated as roads. All of the families have been living in the district for 25 years as informal settlers in areas considered dangerous and, therefore, the families have to be immediately relocated. During the initial interview, the average family size of the members of homeowners is five, of which two families owned their houses, two are renting and eight families are living with their relatives. Since many of the Donnaville community members are living along the prohibited creek, the community members decided to look for a piece of land within their own village to relocate. They found a private land to purchase, which has an area of 350 square meters. The proposed lot was irregular in shape, with very slightly rolling terrain and located inside the subdivision where the members are currently living. In order to purchase the lot, the families plan to acquire a loan from a government housing finance program called the Community Mortgage Program (CMP) and be able to pay the property owner collectively over a 25 year period. As stated earlier, the government initiated Foundation for the Development of the Urban Poor was assisting them with the various requirements, which include schematic plans in order to get their loan approved. As part of this, the families have been assisted technically to come up with some schemes for site layout (Fig. 1a) and house designs (Fig. 1b and Fig. 1c).

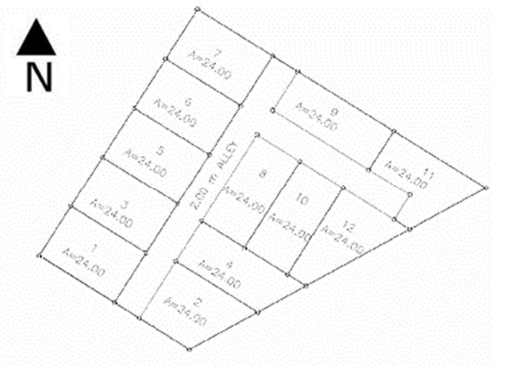

a)

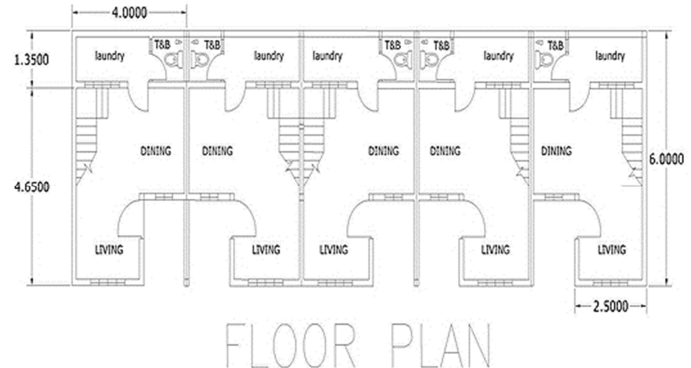

b)

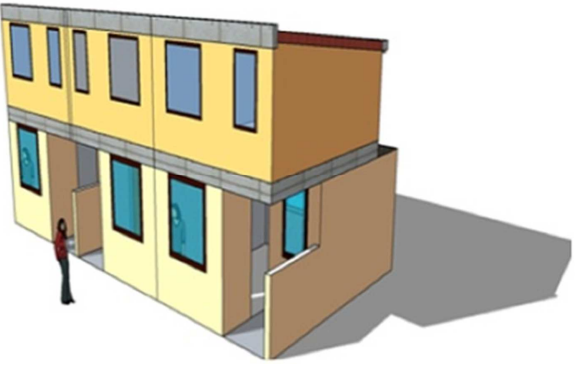

c)

Fig. 1. a) The proposed schematic lot plan; b) proposed floor plan; and c) exterior perspective given by the foundation

The foundation was not able to conduct any consultation with the homeowners regarding the design of the housing unit, thus the resulting cost for each unit was not 
within the financial capabilities of the family members. Furthermore, the foundation failed to consider solutions to problems like flooding and accessibility. The governments and professionals prescribed solutions for the well-being of the poor based on what they deemed proper, without involving the concerned individuals. This topdown type approach is common among government initiated projects [9].

\section{Research methodology}

The methodology used in this study is the Participatory Action Design Research (PADR). In order for this to be effective, researchers must work closely with communities to investigate their concerns, develop proposals for transformative change, and identify new questions to investigate [17]. Embedded in the principles of justice and democracy, the methodology is a collaborative approach to research defined both by participation and a determination to produce knowledge in the interest of social change [18]. The members of community architects decided to initiate the program through a series of workshops. The process of the workshop comprised of six phases:

a) Problem identification;

b) Evaluation of the existing houses;

c) Site visualization and inspection;

d) Visualization of house plans; and

e) Finalizing the schematic designs.

The objective of the workshop was to allow each member to contribute as well as collaborate with the architects and planners. Each family member had a voice in the final decision and outcome of the final plans. Studies have shown that the experiences in the participation process show that the main source of user satisfaction is not the degree to which a person's needs have been met, but the feeling of having influenced the decisions [18].

\subsection{Problem identification}

The workshop began with the problem identification. Problem identification of the present situation is significant in order to recognize its strengths and weaknesses in order to make an action plan. During this workshop, it was identified that most houses of the community members were living near the creek which was declared as a danger zone by the local government authorities. The rest of the houses were built on the roadside, which is not permitted by the local government. During a discussion with Arlene Balansag, the president of the association (Fig. 2), some of the members are renting these houses because they could no longer afford the high cost of living near the city.

During the interview, the families agreed that the schematic designs and the estimated cost of the future houses provided by the foundation were unaffordable for them. The families would like to have an alternative low-cost house design as well as personal inputs on the final design. The families decided that one way to bring the total cost down was to re-use some of the materials in their old houses and incorporate it into 
their new residences. Additionally, the families also would like to have a site that has good drainage and ease of accessibility.

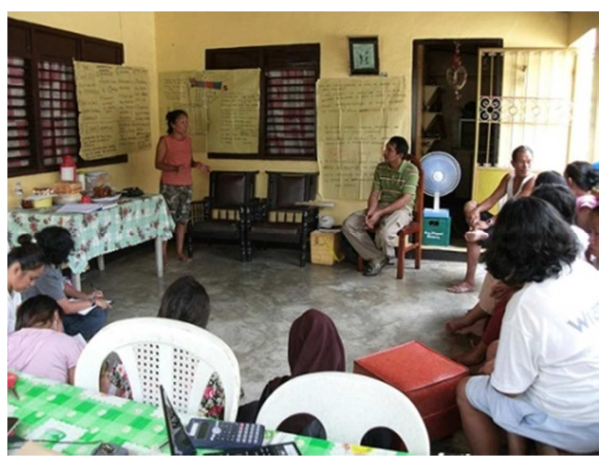

Fig. 2. Arlene Balansag, President of homeowners, presenting their community profile

\subsection{Evaluation of existing houses}

In this phase, the members of the community architects conducted surveys of the houses of the community members (Table $I$ ) and performed interviews. This was completed in order to identify the spatial housing needs of the members in space usage and materials that they can still re-use into their new house.

Table I

Profile of the members of the Donnaville Homeowners Association

\begin{tabular}{|l|c|c|}
\hline \multicolumn{1}{|c|}{ Name } & House Type & Present Location \\
\hline 1. A. Balansag & Partly wooden and concrete with GI Roof & Creek Side \\
2. M. Bagube & Partly wooden and concrete with GI Roof & Creek Side \\
3. A. Decasa & Partly wooden and concrete with GI Roof & Creek Side \\
4. C. Abesia & Partly wooden and concrete with GI Roof & Creek Side \\
5. E. Dublin & Partly wooden and concrete with GI Roof & Road Side \\
6. N. Neuda & Partly wooden and concrete with GI Roof & Road Side \\
7. Y. Bactasolo & All concrete with GI Roof & Creek Side \\
8. Y. Yrinco & All concrete with GI Roof & Creek Side \\
9. E. Gabut & Partly wooden and concrete with GI Roof & Creek Side \\
10. E. Opena & Partly wooden and concrete with GI Roof & Creek Side \\
11. M. Avila & All concrete with GI Roof & Creek Side \\
12. Fuentes & Partly wooden and concrete with GI Roof & Creek Side \\
\hline
\end{tabular}

The members of the community architects proceeded to document the materials that can, therefore, be re-used into their new houses. By recycling these materials, the cost of the new house will, therefore, be significantly lesser and thus made affordable by the families. Only the roof and interior fittings (doors, window frames, and cabinets) were being re-used as suggested by the engineers and agreed by the members of the families. 


\subsection{Site visualization and inspection}

The first part of this workshop is the site visualization and inspection. The families, together with the community architects, visited the relocation site and performed two activities. First, a lot staking out activity was performed in order to easily visualize the site to the members of the families. Lot staking out was done to easily visualize the corners and boundaries of the proposed relocation site in order easily assess the general location and situation of the lot. The schematic site (Fig. 3) development plan, which was earlier provided to the community, was used as a reference.

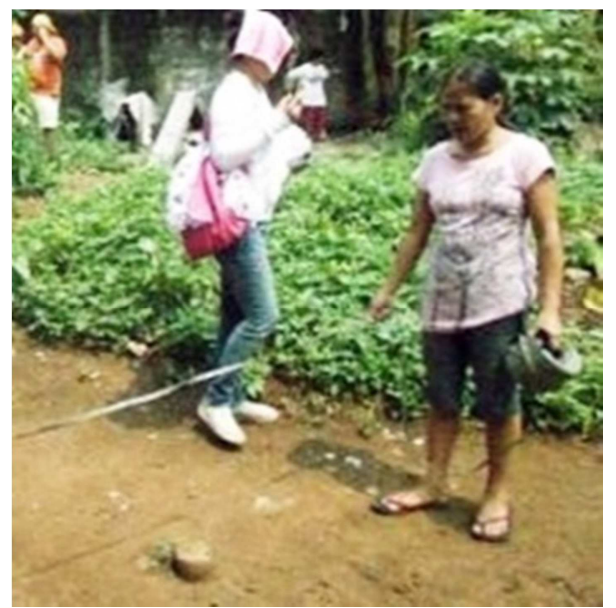

Fig. 3. A member doing the plot staking out of the proposed site

This activity helped the participants visualize the given housing plot layouts, common alleys and possible open space. All 12 members decided that each would be provided with an individual lot, subdivided from the 350 square meters lot area. However, the irregular shape of the property caused the uneven plotting of the individual lots. The community architects, therefore, re-examined the existing schematic site development plan given to them by the foundation. The community architects then produced an alternative plot layout by analyzing the needs and requirements of each of the families. During the discussion, the community architects noted that one of the most important desires is to have ease of access to their new homes. Because of this, the families have agreed to have an investigation of the common alleyway. A two meter wide common alleyway was tested as to its practicability in line with the everyday activities of the homeowners. For instance, walking (Fig. 4) along the alleyway (with or without umbrellas) and alighting from a tricycle, the most common mode of public transportation in the area. In order to easily visualize this space to the family members, the community architects placed markers on the ground in order to better understand the different distance across the alleyway. This assessment resulted in the decision of the homeowners to widen the common alley to three meters because they felt that this is more sensible and comfortable. 


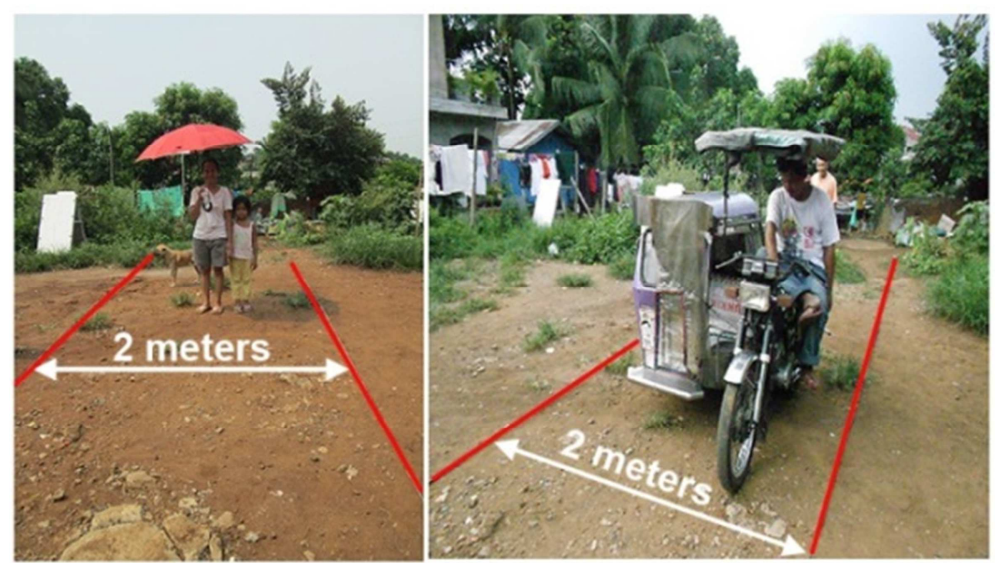

Fig. 4. An Analysis of the two meter wide alleyway

The second part of the workshop involves site planning and space analysis of the new site. For this activity, the community architects separated the homeowners into two working groups and were given a scaled drawing of the Lot Plan. The groups were given large sheets of drawing paper to cut out the twelve individual plot sizes according to scale and arrange the new possible layout of lots. During this stage, it is important that the architects and designers facilitate, enable and empower the members of the group in their site planning output. Finally, the two working groups then presented their output (Fig. 5a) for further discussions among the community members. It was interesting to note that both groups tried to position the individual lots around the perimeter, leaving the central area open (Fig. $5 b$ ). The planned central space was clearly absent in the schematic lot plan provided by the foundation.

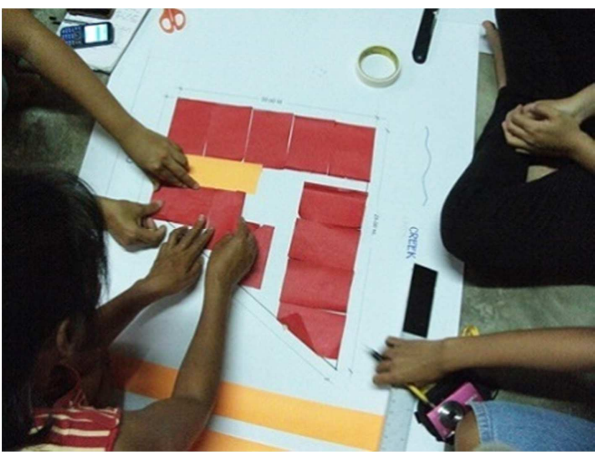

a)

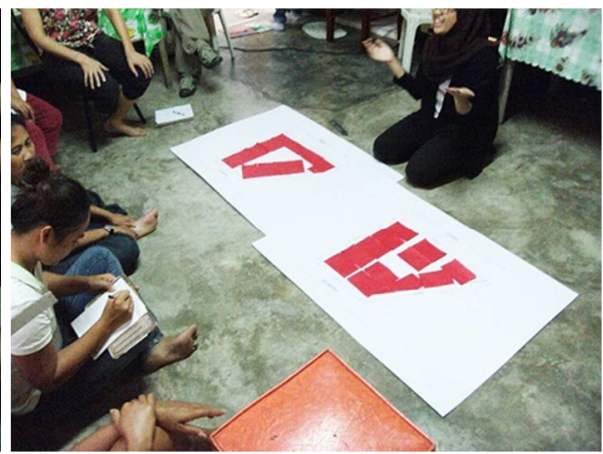

b)

Fig. 5. a) Site plan discussions among the two groups; b) site with a central open area

The resulting analysis and study of the two groups was a revised site plan that includes a main common alley with a three meter width, a two meter wide access alley 
to the inner lots and a one meter service alley that connects to the creek for purposes of drainage outfall (Fig. 6). The final site layout had an open communal space in the middle, which can serve as a multi-functional space. The desire to connect with other family members of the community is one of the cultural traits of the Filipino people [19].

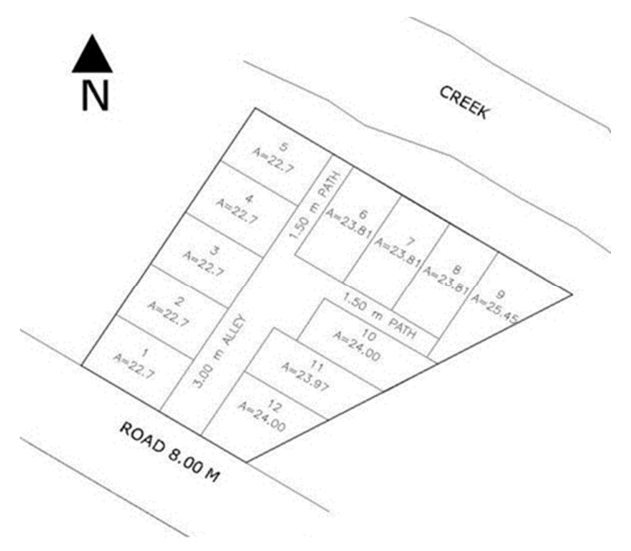

Fig. 6. The revised schematic lot plan

\subsection{Visualization of house plans}

Before introducing the process of visualizing the house plans, the community architects gave a short discourse on Batas Pambansa 220, otherwise known as the Socialized and Economic Housing Act of the Philippines. This is a national housing act law that discusses the government standards on lot sizes as well as proper house standards, which must be strictly observed. This lecture is significant since one of the objectives of participatory design is to also impart knowledge to the community [18], especially regarding government regulations on house standards. The visualization of the house plans started by introducing the family members on how to visualize the spaces (Fig. 7) in the house based on their daily activities on a $1 \mathrm{x} 1$ meter (1 square meter) large format paper. By using the paper as tangible materials, the individual families were able to find it easier to visualize the use functional spaces.

Next, the community architects gathered the community members into three working groups. Each group was instructed to design their house layout based on an allocated lot of dissimilar configurations (Fig. 8). In order to easily visualize the measurements, the community architects prepared several cutout squares representing one square meter at a scale corresponding to the illustrated lot. They were further instructed to lay out the squares based on their specific needs of the space while the architects provided guidance. These squares that were set on the site plot later formed into a rough floor plan. The three groups then presented and explained their house layout to the community architects. This activity gave the groups the opportunity to modify their designs as suggested by the community architects. 


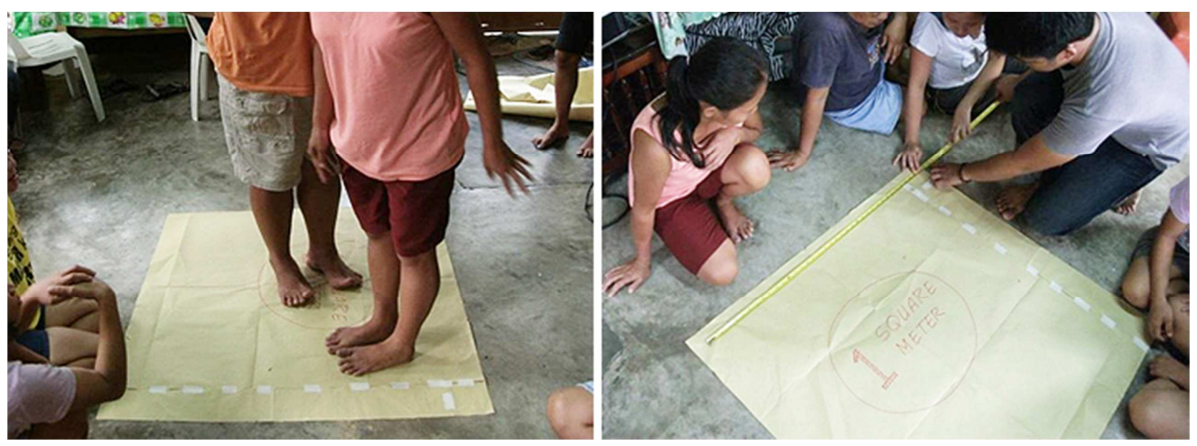

Fig. 7. Visualizing the one square meter block

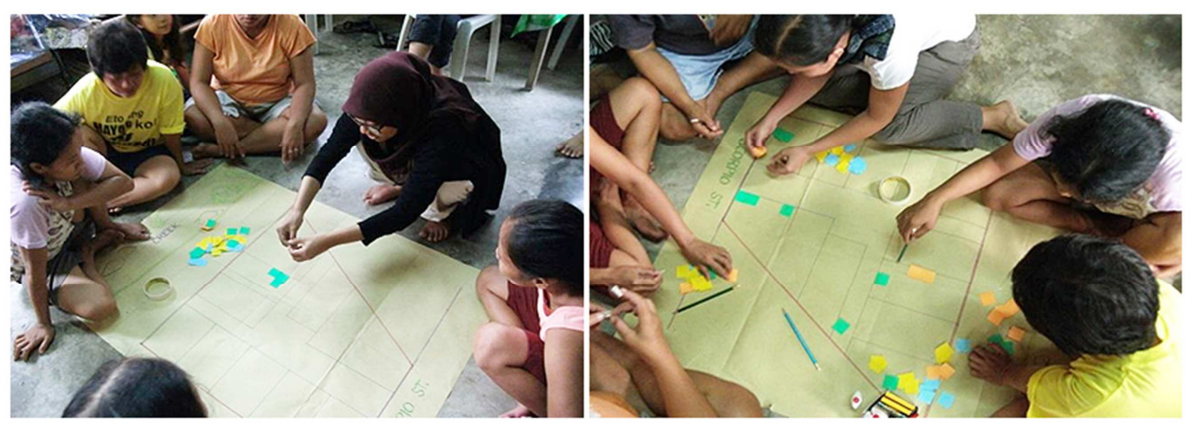

Fig. 8. House visualization and layout exercises

In this exercise, it was observed that all three groups desire for a second floor in the future for extended families. Therefore, the group members left an empty space on the ground floor so that a future stairway can be constructed. In Filipino culture, families form a strong bond and it is common to have an extended family. All of these suggestions were documented and analyzed by the community architects as a guide for the final floor plan of the new houses. The recommendations are as follows:

a) No interior walls (open space concept);

b) Front and rear spaces for services (laundry);

c) Simple one story construction;

d) Allocate stairway for future expansion at the second floor;

e) Place the entrance of the toilet inside;

f) Place the kitchen outside with roof;

g) Allocate toilet size of $1 \times 1.5$ meters; and

h) Toilet door must not align the main door.

Based on these feedbacks and suggestions from the family members, the community architects proceeded with the finalization of the schematic designs. 


\subsection{Finalizing the schematic designs}

In this workshop, the technical drawings, bill of materials and cost estimates were being finalized by community architects with the recommendations of the family members. The workshop also allowed the families to gain knowledge and understanding of building materials, cost estimation and the process of building construction. The families agreed to use conventional materials of reinforced concrete and galvanized iron roofing sheets while the structure of the house was also considered to allow a secondfloor future expansion. By using concrete and galvanized iron roofing, the families achieve a sense of security, physical and mental comfort as well as an elevation of social class. Further cost reduction strategies were suggested by the architects, for instance, a communal septic tank was decided by the family members to reduce sanitary drainage cost and a lean-to roof design was incorporated to encourage rainwater harvesting. Furthermore, the lean-to roof design can be easily hoisted when the families can eventually afford for a second-floor expansion in the future. After the analysis, the cost estimate of the house was US\$ 2,947 (labor and materials). The resulting cost was in favourable with the families because the monthly amortization was reasonably priced and within the means of the family members. The community architects finalized the twelve floor plans and drainage plan (Fig. 9a) by integrating them into the final site development plan (Fig. 9b).

a)

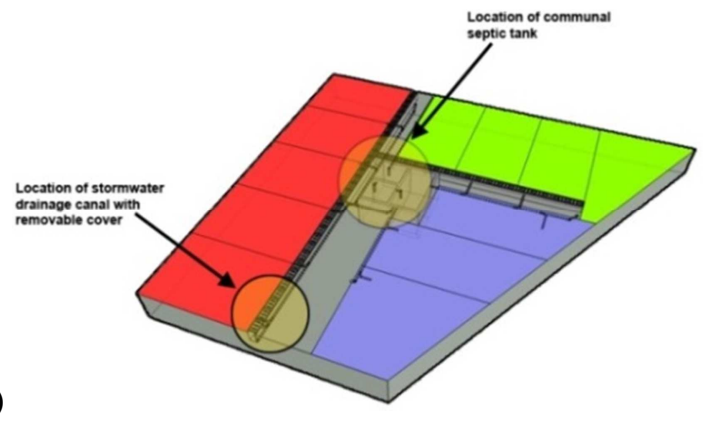

b)

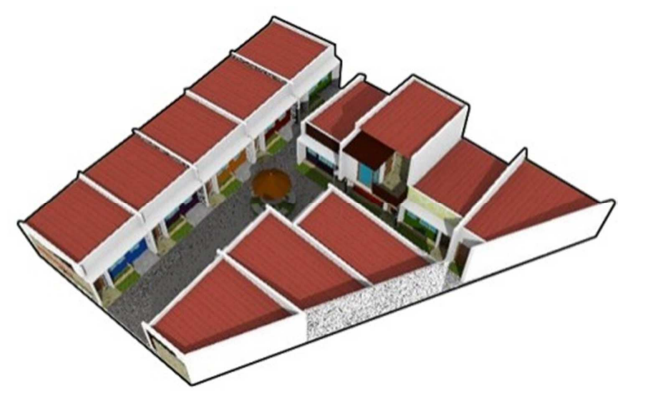

Fig. 9. a) Location of storm water drainage and communal septic tank; b) Perspective of the final site development plan 
Finally, the final schematic designs, site layout, construction documents and estimates were presented to the homeowners (Fig. 10) in order for them to apply for a financial loan through the foundation.

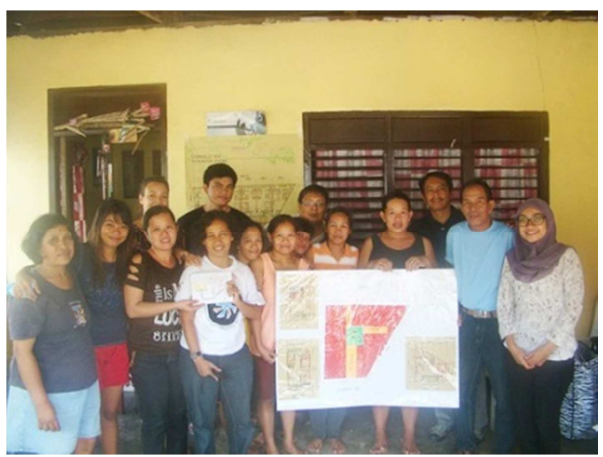

Fig. 10. The final floor plan and perspective of the future homes of the families

\section{Conclusion}

This study shows how the use of participatory design was effective in identifying numerously feasible and cost-effective strategies in the development of an affordable housing for the families of Donnaville Homeowners Association. By using Participative Design Workshops, the community members were actively involved in addressing their concerns as to come up with alternative designs of their houses in addition to the knowledge in building materials, cost estimation and construction. These Participative Design Workshops can be complex and requires the contribution of several actors within the different developmental phases. Each participant is important in contributing to the overall development of the project and the project cannot be realized without the involvement of all the actors. The workshop resulted in a housing unit which was affordable and beneficial to the members of the association. Although the workshop proved to be very challenging due to different personalities and technical issues, the use of participatory design still validates the effectiveness in community planning. Finally, the use of participatory design as a methodology for community improvement should be assimilated in the future design curriculum for planning courses of the universities.

\section{Acknowledgements}

This work was made possible by the Community Architects Network. The members are: Ar. Ariel Shepherd, Ar. Christopher Ebreo, Ar. Cesar Aris, Ar. Liza Utami Marzaman, Ar. Sriana Delfiati, Ar. Jemielin Legaspi, Chawanad Luansang, Maria Lourdes Domingo-Price, Engr. Noel Zeta and Engr. Carlo Bongac. Finally, the members of the Peoples Action for Community-led Shelter initiatives and the Institute of Planning and Design, SAFAD (University of San Carlos-Technological Center). 


\section{References}

[1] Somsook B., Kerr T. How urban poor community leaders define and measure poverty, Environment and Urbanization, Vol. 27, No. 2, 2015, pp. 637-656.

[2] Teaford, J. C. Urban renewal and its aftermath, Housing Policy Debate, Vol. 11, No. 2, 2000, pp. 443-465.

[3] Couch C. Urban renewal: theory and practice, Macmillan, 1990.

[4] Wates N., Knevitt C. Community architecture, How people are creating their own environment, Routledge Revivals, 2013.

[5] Ferreira R. Community-based coping: an HIV/AIDS case study, Community Psychology: Analysis, Context and Action, 2007, pp. 380-391.

[6] Portschy Sz. Design partnerships between community-engaged architecture and academic education programs, Pollack Periodica, Vol. 10, No. 1, 2015, pp. 173-180.

[7] Portschy Sz. Community participation in sustainable urban growth, case study of Almere, the Netherlands, Pollack Periodica, Vol. 11, No. 1, 2016, pp. 145-155.

[8] McCarthy J., Wright P. Taking apart: the politics and aesthetics of participation in experience-centered design, Cambridge, MA, The MIT Press, 2015.

[9] Toker Z. Recent trends in community design: the eminence of participation. Design Studies, Vol. 28, No. 3, 2007, pp. 309-323.

[10] Wates N., Brook J. The community planning handbook: How people can shape their cities, towns and villages in any part of the world, Routledge, 2014.

[11] Muller M. J., Kuhn S. Participatory design, Communications of the ACM, Vol. 36, No. 6, 1993, pp. 24-29.

[12] Gennari R., Melonio A., Raccanello D., Brondino M., Dodero G., Pasini M., Torello S. Children's emotions and quality of products in participatory game design, International Journal of Human-Computer Studies, Vol. 101, 2017, pp. 45-61.

[13] Bjögvinsson E., Ehn P., Hillgren, P. A. Design things and design thinking: Contemporary participatory design challenges, Design Issues, Vol. 28, No. 3, 2012, pp. 101-116.

[14] Bjerknes G., Ehn P., Kyng M., Nygaard K. Computers and democracy: A Scandinavian challenge, Gower Pub Co, 1987.

[15] Ravina D., Shih R. R. A shelter for the victims of the Typhoon Haiyan in the Philippines: The design and methodology of construction, Pollack Periodica, Vol. 12, No. 2, 2017, pp. 129-139.

[16] Robertson T., Simonsen J. Challenges and opportunities in contemporary participatory design, Design Issues, Vol. 28, No. 3, 2012, pp. 3-9.

[17] Torre M. E., Cahill C., Fox M. Participatory action research in social research international encyclopedia of the social and behavioral sciences, (2nd ed, pp. 540-544), Oxford, Elsevier, 2015.

[18] Sanoff H. Multiple views of participatory design, International Journal of Architectural Research, Vol. 2, No. 1, 2008, pp. 57-69.

[19] Lorenzo A. C. M. Filipino culture of Filling up space in a gated community, Procedia Social and Behavioral Sciences, vol. 216, 2016, pp. 545-551. 